\title{
Abnormal Tau Phosphorylation in the Thorny Excrescences of CA3 Hippocampal Neurons in Patients with Alzheimer's Disease
}

\author{
Lidia Blazquez-Llorca a,b,c,1, Virginia Garcia-Marin ${ }^{\mathrm{d}, 1}$, Paula Merino-Serrais ${ }^{\mathrm{a}, \mathrm{b}, \mathrm{c}}$, Jesús Ávila ${ }^{\mathrm{c}, \mathrm{e}}$ \\ and Javier DeFelipe ${ }^{\mathrm{a}, \mathrm{b}, \mathrm{c}, *}$ \\ ${ }^{a}$ Laboratorio de Circuitos Corticales (CTB), Universidad Politécnica de Madrid, Campus Montegancedo S/N, \\ Pozuelo de Alarcón, Spain \\ ${ }^{\mathrm{b}}$ Instituto Cajal (CSIC), Madrid, Spain \\ ${ }^{\mathrm{c}}$ Centro de Investigación Biomédica en Red sobre Enfermedades Neurodegenerativas (CIBERNED), Madrid, Spain \\ ${ }^{\mathrm{d}}$ Center for Neural Science, New York University, New York, NY, USA \\ eCentro de Biología Molecular "Severo Ochoa" (CSIC-UAM), C/ Nicolás Cabrera 1, Campus de Cantoblanco, \\ Universidad Autónoma de Madrid, Madrid, Spain
}

Accepted 9 May 2011

\begin{abstract}
A key symptom in the early stages of Alzheimer's disease (AD) is the loss of declarative memory. The anatomical substrate that supports this kind of memory involves the neural circuits of the medial temporal lobe, and in particular, of the hippocampal formation and adjacent cortex. A main feature of AD is the abnormal phosphorylation of the tau protein and the presence of tangles. The sequence of cellular changes related to tau phosphorylation and tangle formation has been studied with an antibody that binds to diffuse phosphotau (AT8). Moreover, another tau antibody (PHF-1) has been used to follow the pathway of neurofibrillary (tau aggregation) degeneration in $\mathrm{AD}$. We have used a variety of quantitative immunocytochemical techniques and confocal microscopy to visualize and characterize neurons labeled with AT8 and PHF-1 antibodies. We present here the rather unexpected discovery that in $\mathrm{AD}$, there is conspicuous abnormal phosphorylation of the tau protein in a selective subset of dendritic spines. We identified these spines as the typical thorny excrescences of hippocampal CA3 neurons in a pre-tangle state. Since thorny excrescences represent a major synaptic target of granule cell axons (mossy fibers), such aberrant phosphorylation may play an essential role in the memory impairment typical of AD patients.
\end{abstract}

Keywords: Alzheimer's disease, glutamatergic terminals, hippocampal formation, tau protein, thorny excrescences

\footnotetext{
Both authors contributed equally this work.

*Correspondence to: Javier DeFelipe, Laboratorio Cajal de Circuitos Corticales (CTB), Universidad Politécnica de Madrid, Campus Montegancedo S/N, Pozuelo de Alarcón, 28223 Madrid; or Instituto Cajal (CSIC), Avenida Doctor Arce 37, 28002 Madrid, Spain. Tel.: (+34) 91452 4900, ext. 1934; E-mail: defelipe@cajal.csic.es or, Jesús Ávila, Centro de Biología Molecular "Severo Ochoa", C/ Nicolás Cabrera 1, Campus de Cantoblanco, Universidad Autónoma de Madrid, 28049 Madrid, Spain. Tel.: (+34) 91196 4564; E-mail: javila@cbm.uam.es.
}

\section{INTRODUCTION}

Alzheimer's disease (AD) is a progressive neurodegenerative disease partially characterized by the accumulation of neurofibrillary tangles (NFT) containing hyperphosphorylated tau, the major protein subunit of paired helical filaments (PHF) [1]. The memory deficits provoked in AD may be associated with neuronal loss, which commences in the hippocampal region and is possibly related to the impaired adult neurogenesis in the dentate gyrus, as it has been reported 
in $\mathrm{AD}$ and in some animal models [2]. Newborn neurons form functional synapses with CA3 neurons and the axons that adult generated dentate gyrus neurons emit synapse with the thorny excrescences of CA3 neurons [3]. Abnormally phosphorylated tau is the major component of tangles [1] and this event precedes tau aggregation. The sequence of cellular changes related to tau phosphorylation and the formation of tangles has been studied with a tau antibody that binds to diffuse phophotau (AT-8) [4]. Moreover, another tau antibody (PHF-1) has been used to follow the pathway of neurofibrillary (tau aggregation) degeneration in $\mathrm{AD}$ [5]. Accordingly, diffuse cytoplasmic PHF-tau reactivity is thought to reflect an altered neuronal state (pre-tangle) that precedes the formation of compacted NFT [6]. PHF-tau is typically found in the soma, dendrites, and axons, although during the course of our microanatomical and neurochemical studies on the brain of $\mathrm{AD}$ patients, we observed an impressive and consistent Golgi-like labeling of the typical thorny excrescences of pyramidal cells and mossy cells of the hippocampal CA3 field (Fig. 1). This Golgi-like labeling was evident in virtually all neurons with diffuse cytoplasmic PHF-tau immunostaining. Thus, the main goal of the present work was to study in detail the PHF-tau positive dendritic spines in CA3, and to assess whether dendritic spines are also labeled in those pyramidal neurons that express PHF-tau in other areas of the hippocampal formation and neocortex. In addition, we used double labeling immunocytochemistry and confocal microscopy to examine whether PHF-tau positive thorny excrescences are innervated by glutamatergic terminals.

\section{MATERIAL AND METHODS}

Human brain tissue was obtained at autopsy from two sources: 11 patients with AD (aged 72-94, mean 83.1); and control human brain tissue from 7 individuals (aged 23-69, mean 49.4) who died in accidents and were free of any known neurological or psychiatric illness (Table 1). The AD brain tissues were obtained from the Instituto de Neuropatología (Dr. I. Ferrer, Servicio de Anatomía Patológica, IDIBELL-Hospital Universitario de Bellvitge, Barcelona, Spain) and from the Banco de Tejidos Fundación CIEN (Dr. A. Rábano, Área de Neuropatología, Centro Alzheimer, Fundación Reina Sofia, Madrid, Spain). The control human brains were obtained from the Servicio de Patología Forense (Dr. R. Alcaraz, Instituto Vasco de Medicina Legal, Bilbao, Spain). Following a neuropathological exami- nation, the patients' AD stage was defined according to Braak and Braak [19] (Table 1). Control cases (C1-C7) were associated with different scores for the amyloid and neurofibrillary pathologies. While $\mathrm{C} 1$ and $\mathrm{C} 5-7$ had a Braak score of zero for both pathologies, C2-3

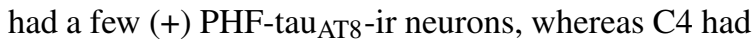
many $(+++)$. Finally, while $\mathrm{C} 2$ developed numerous $(+++)$ plaques immunostained for amyloid- $\beta$ (A $\beta)$, there were no such plaques in cases C3-4 [20]. In all cases, the time between death and tissue processing was between 1.5 and $3 \mathrm{~h}$, and the brain samples were obtained with the approval of and according to the guidelines of the Institutional Ethical Committee.

Upon removal, the brain tissue was immediately fixed in cold $4 \%$ paraformaldehyde in phosphate buffer (PB: 0.1 M, pH 7.4) and after $2 \mathrm{~h}$, the tissue was cut into small blocks and post-fixed in the same fixative for $24-48 \mathrm{~h}$ at $4^{\circ} \mathrm{C}$. After fixation, all the specimens were immersed in graded sucrose solutions and they were stored in a cryoprotectant solution at $-20^{\circ} \mathrm{C}$. Serial vibratome sections $(50 \mu \mathrm{m})$ of cortical tissue were obtained, and the sections from each region and case were batch-processed for immunocytochemical staining. The sections immediately adjacent to those stained immunocytochemically were Nissl-stained to identify the cortical areas to which they pertained and the laminar boundaries.

\section{Immunohistochemistry}

Free-floating sections were pre-treated in $1 \% \mathrm{H}_{2} \mathrm{O}_{2}$ for $30 \mathrm{~min}$ to inactivate the endogenous peroxidase activity and subsequently, they were blocked for $1 \mathrm{~h}$ in PB with $0.25 \%$ Triton-X and 3\% normal goat or horse serum (for polyclonal antisera and monoclonal antibodies, respectively: Vector Laboratories Inc., Burlingame, CA, USA). Single immunohistochemistry was performed with the following polyclonal antiserum or monoclonal antibodies: guinea pig antivesicular glutamate transporter 1 polyclonal antiserum (VGLUT-1, 1:5000, AB5905: Chemicon); monoclonal mouse anti-human $\mathrm{A} \beta$ antibody (clone 6F/3D diluted 1 : 50; Dako, Glostrup, Denmark); mouse antihuman PHF-tau monoclonal antibody (clone AT8, PHF-tau $_{\text {AT8; }} 1: 2000$, MN1020: Thermo Scientific; Waltham, MA, USA); mouse PHF-1 monoclonal antibody (PHF-tauPHF-1; $1: 100$, kindly supplied by Dr. P. Davies); and mouse Tau-1 monoclonal antibody ( $1: 1000$, kindly supplied by Dr. L. Binder).

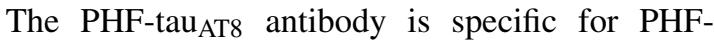
tau doubly phosphorylated at Ser202 and Thr205. It has also been shown to cross-react with tau dou- 

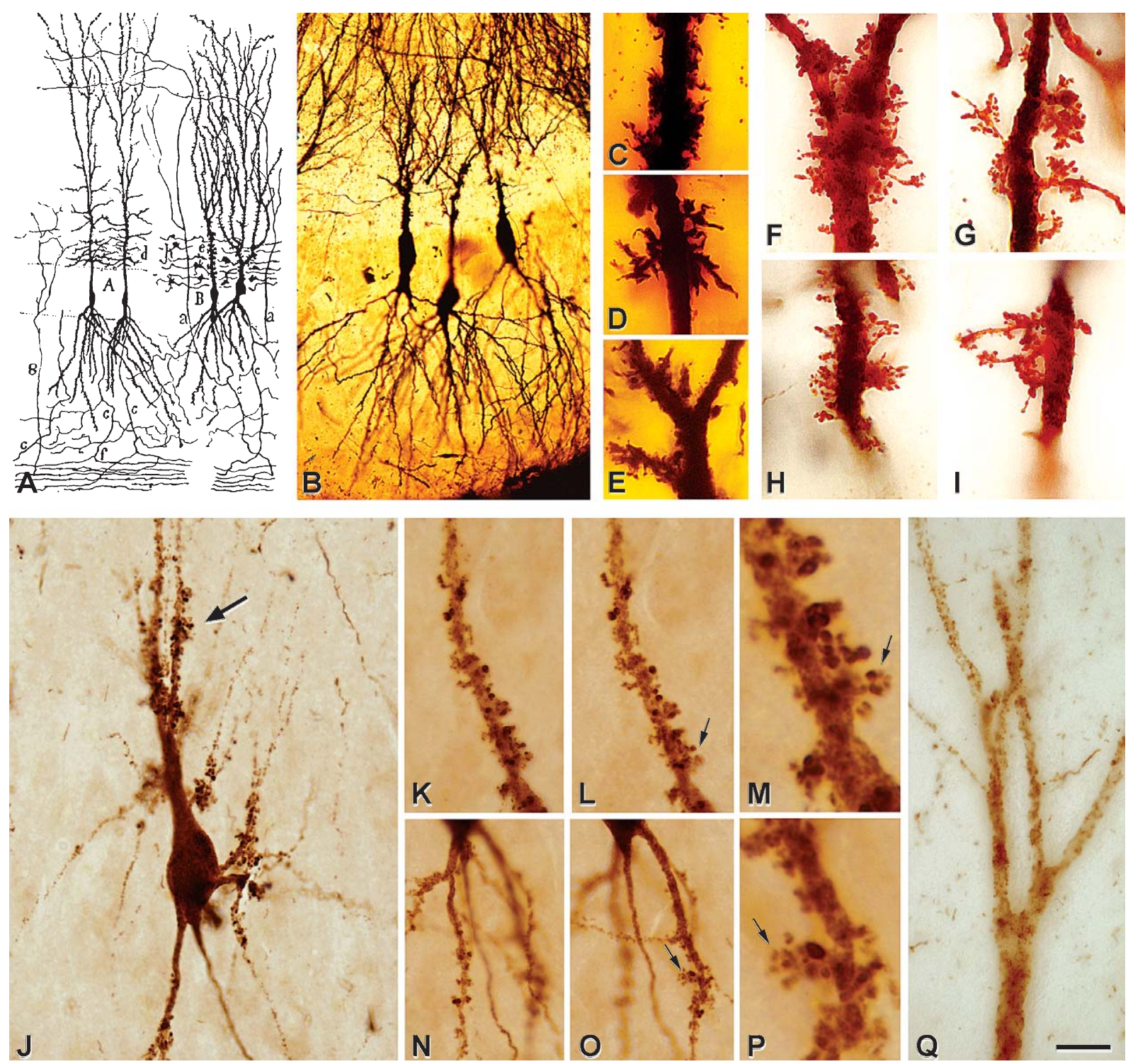

Fig. 1. A) Cajal's drawing showing pyramidal cells with thorny excrescences in the CA3 [7]. B) Cajal's original histological preparations from the rabbit CA3 stained by the Golgi method. C-I), Examples of thorny excrescences on CA3 pyramidal neurons. C-E) Dendrites from a newborn child's CA3 pyramidal neurons stained by the Golgi method; F-I) Dendrites on rabbit CA3 pyramidal neurons stained by the Kenyon's variant of the Golgi method (preparations housed at the Cajal Institute). Thorny excrescences were named and discovered by Cajal in the apical dendrites of rabbit CA3 pyramidal neurons [7]. He correctly proposed that these large and often branched structures served as points of contact with the mossy fibres from the dentate gyrus. The presence of excrescences was later confirmed in a variety of species, including humans, both in the apical and basal dendrites and in the hilar mossy cells [8-17]. These complex dendritic spines represent a major target of the axon terminals (mossy fibres) of hippocampal dentate granule cells. The thin unmyelinated mossy fibres form numerous large, en passant swellings and terminal

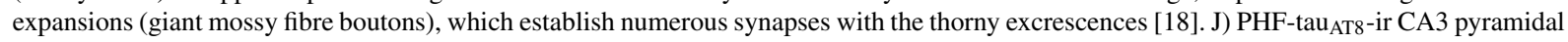
neuron from patient $\mathrm{P} 4$ exhibiting a cluster of thorny excrescences (arrow). K-L, N-O) Two focal planes showing thorny excrescences on CA3

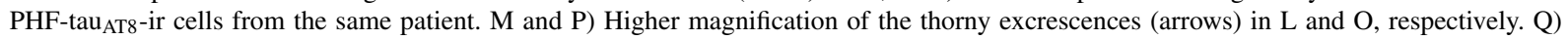
Apical dendritic shaft of a type I CA2 PHF-tau ${ }_{\mathrm{AT}}$-ir pyramidal cell with no labelled dendritic spines. Scale bar (in Q): $55 \mu \mathrm{m}$ in B; $11 \mu \mathrm{m}$ in $\mathrm{C}-\mathrm{I} ; 25 \mu \mathrm{m}$ in $\mathrm{J} ; 20 \mu \mathrm{m}$ in $\mathrm{K}, \mathrm{L}, \mathrm{N}, \mathrm{O} ; 4 \mu \mathrm{m}$ in M, P; $10 \mu \mathrm{m}$ in Q.

bly phosphorylated at Ser199/202 and Ser205/208 [21] while PHF-tauPHF-1 recognizes tau phosphorylated at Ser396 and Ser404 [22]. Tau-1 is an antibody that recognizes a non-phosphorylated epitope of tau that contains Ser199/Ser202 (of human tau441). The sections were incubated overnight at $4{ }^{\circ} \mathrm{C}$ with the anti- 
Table 1

Summary of case data

\begin{tabular}{|c|c|c|c|c|c|}
\hline $\begin{array}{l}\text { AD } \\
\text { patient }\end{array}$ & Age & Gender & $\begin{array}{l}\text { NF/A } \beta \text { pathology } \\
\text { Braak stage }\end{array}$ & $\begin{array}{l}\text { Postmortem } \\
\text { delay (h) }\end{array}$ & Cause of death \\
\hline P1 & 80 & Female & AD IV/B & 2 & - \\
\hline $\mathrm{P} 2$ & 94 & Female & $\mathrm{AD} V / \mathrm{C}$ & 1.5 & Pulmonary tuberculosis \\
\hline P3 & 82 & Female & AD III/B & 3 & Pneumonia \\
\hline P4 & 80 & Female & AD III (TAD*) & 3 & $\begin{array}{l}\text { Pseudomembranous colitis plus sepsis and } \\
\text { sancreatic adenocarcinoma }\end{array}$ \\
\hline P5 & 85 & Male & AD III/A and AGD & 2 & Pneumonia plus interstitial pneumonitis \\
\hline P6 & 88 & Female & AD III (TAD*) and AGD & 2 & Bronchopneumonia \\
\hline P7 & 91 & Male & AD III/A and AGD & 3 & Hepatocarcinoma \\
\hline P8 & 72 & Male & AD I (TAD*) and AGD & 2 & Bronchopneumonia \\
\hline P9 & 82 & Male & $\mathrm{AD} \mathrm{V} / \mathrm{C}$ & 3 & Bronchopneumonia plus cardiac failure \\
\hline P10 & 85 & Male & $\mathrm{AD} \mathrm{V}-\mathrm{VI} / \mathrm{C}$ & 1.5 & - \\
\hline P11 & 75 & Male & AD III/B and AGD & $2-2.5$ & Lymphoproliferative disorder \\
\hline $\begin{array}{l}\text { Control } \\
\text { (autopsies) }\end{array}$ & & & $\begin{array}{l}\text { NF/A } \beta \text { pathology } \\
\text { (hippocampal formation) }\end{array}$ & & \\
\hline $\mathrm{C} 1$ & 23 & Male & 0 & $2-3$ & Traffic accident \\
\hline $\mathrm{C} 2$ & 49 & Male & $\begin{array}{l}\text { (+)PHF-tau } \\
\text { (+++) } \mathrm{A} \beta \text { plaques neurons }\end{array}$ & $2-3$ & Traffic accident \\
\hline C3 & 69 & Male & $\begin{array}{l}\text { (+)PHF-tau } \\
\text { (0) A } \mathrm{A} \beta \text { plaques }\end{array}$ & $2-3$ & Traffic accident \\
\hline $\mathrm{C} 4$ & 63 & Female & $\begin{array}{l}(+++) \text { PHF-tau } \\
\text { AT8-ir neurons } \\
\text { (0) A } \beta \text { plaques }\end{array}$ & 3 & Traffic accident \\
\hline C5 & 36 & Male & 0 & $2-2.5$ & Traffic accident \\
\hline C6 & 40 & Male & 0 & 3 & Traffic accident \\
\hline $\mathrm{C} 7$ & 66 & Male & 0 & 3 & $\begin{array}{l}\text { Bilateral pneumonia plus cardiac } \\
\text { post-transplant }\end{array}$ \\
\hline
\end{tabular}

A $\beta$, Amyloid- $\beta$. AGD, Argyrophilic grain disease. NF, Neurofibrillar. TAD*, Tangle-predominant variant of Alzheimer's disease.

bodies described above (PHF-tau ${ }_{\mathrm{AT}}$, PHF-tau PHF-1 and Tau-1 immunostaining), and the following day, the sections were rinsed and incubated for $2 \mathrm{~h}$ with biotinylated goat anti-guinea-pig $\operatorname{IgG}(1: 200$, BA-7000: Vector Laboratories: VGLUT-1 immunostaining) or biotinylated horse anti-mouse IgG (1:200, BA-2000: Vector Laboratories). The sections were then incubated for $1 \mathrm{~h}$ in an avidin-biotin peroxidase complex (Vectastain ABC Elite PK6100, Vector), and finally with the 3,3'diaminobenzidine tetrahydrochloride chromogen (DAB: Sigma-Aldrich, St. Louis, MO, USA). After staining, the sections were dehydrated, cleared with xylene and coverslipped. Some slices immunostained for $\mathrm{A} \beta$ and for PHF-tau $\mathrm{AT} 8$ were counterstained by the Nissl technique to visualize the hippocampal strata.

\section{Dual fluorescence immunohistochemistry and histochemistry}

To ascertain the relationship between neurons immunocytochemically stained for either PHF-tau or PHF-tauPHF-1, and neurons histochemically labeled for Thioflavine-S to visualize NFT, some sections were stained using the same anti-PHF-tau AT8 $_{\text {and }}$ PHF-tauPHF-1 antibodies at the dilutions and incubation times indicated above. Thereafter, the sections were incubated for $2 \mathrm{~h}$ at room temperature with the
Alexa fluor conjugated goat-anti mouse 594 antibody $(1: 2,000$, Molecular Probes, Eugene, OR). After rinsing the sections in $\mathrm{PB}$, they were incubated for $10 \mathrm{~min}$ in a $1 \%$ solution of Thioflavine-S and they were then rinsed for $5 \mathrm{~min}$ in $100 \%, 70 \%$, and then $50 \%$ ethanol. After rinsing in $\mathrm{PB}$, the sections were treated with Autofluorescence Eliminator Reagent (Chemicon) to reduce lipofucsin like-autofluorescence without adversely affecting any other fluorescent labeling in the sections.

To examine the innervation of PHF-tau $\mathrm{AT}$-ir neurons, some sections were double stained with a mixture of antibodies VGLUT-1/PHF-tau ${ }_{\mathrm{AT}}$. The same primary antibodies, dilutions, and incubation times were used as those indicated above. Free-floating sections were incubated overnight at $4{ }^{\circ} \mathrm{C}$ in a solution containing the primary antibodies and then for $2 \mathrm{~h}$ at room temperature with a biotinylated goat anti-guinea pig antibody for VGLUT-1/PHF-tau $\mathrm{AT} 8$ (1:200: Vector). After rinsing in $\mathrm{PB}$, the sections were incubated for $2 \mathrm{~h}$ at room temperature with streptavidin coupled to Alexa fluor 488 (1:2,000, Molecular Probes, Eugene, OR) and with Alexa fluor goat-anti mouse 594. After rinsing in $\mathrm{PB}$, the sections were treated with the Autofluorescence Eliminator Reagent.

Finally, the sections were washed and mounted with ProLong Gold Antifade Reagent (Invitrogen Corpora- 
tion, Carlsbad, CA), and they were examined on a Zeiss LSM 710 confocal laser scanning system equipped with an argon/krypton mixed gas laser with excitation peaks at 488 and $594 \mathrm{~nm}$. The fluorescence of Alexa 488 and 594 was recorded through separate channels. We obtained image stacks that consisted of 18-49 image planes. Both 40x oil-immersion (NA, 1.25 , refraction index, 1.52 ) and $63 \mathrm{x}$ oil-immersion (NA, 1.40, refraction index, 1.45) lenses were used, in some cases with a calculated optimal zoom factor 2.3 .

\section{Quantitative and statistical analyses}

Unbiased stereology was used to quantify total neuron density and PHF-tau ${ }_{\mathrm{AT}}$-ir neuron density in sections taken from similar parts of the CA3 hippocampal region of control and AD patients. The Stereo Investigator software (Microbrightfield, Colchester, VT) was used to drive a motorized stage (Prior Scientific, Houston, TX) on a dual optical head microscope (Olympus $\mathrm{BX} 51$ ), and to mark neurons at 40x (NA, 0.85) under brightfield optics. The software sequentially chose random counting frames in the xyz axes $(60 \times 60 \mu \mathrm{m}$ and $100 \times 100 \mu \mathrm{m}$, to count the total neuron density and PHF-tau ${ }_{\mathrm{AT} 8}$-ir neuron density, respectively), automatically moving the motorized stage within the previously delimited zones of the CA3 region.

To obtain homogeneous estimates of neuron density, tissue shrinkage was evaluated using StereoInvestigator software at five random points in three different sections of each case to estimate shrinkage in the $z$ axis of sections after processing for Nissl staining, or in anti-PHF-tau $_{\text {AT8 }}$ stained Nissl counterstained sections.

The number of labeled neurons was estimated using the optical fractionator method in Stereo Investigator. Neurons were only marked if their edges lay within the dissector area and they did not intersect forbidden lines, and if they came into the focus as the optical plane moved through the height of the dissector $(10 \mu \mathrm{m})$. The guard zone thickness was set as $3 \mu \mathrm{m}$. This sampling method and the section interval were tested in a pilot experiment to ensure that the number of neurons estimated was representative of the total number. The total neuron density was estimated by counting nucleoli in 3-6 Nissl stained sections per case. Neurons with more than one nucleolus were rare but in such cases, only one nucleolus was counted. In terms of the density in PHF-tau ${ }_{\mathrm{AT}}$-ir neurons, we analyzed 3-6 anti-PHFtau $_{\text {AT8 }}$ stained and Nissl counterstained sections per case. In both circumstances, the density obtained was presented in reference to the total volume estimated in each counting analysis. The density of PHF-tau AT $_{8}$-ir neurons was represented as the percentage with respect to the total neuron density obtained per case. Furthermore, a BX51 Olympus microscope equipped with a motorized stage and the Neurolucida package (MicroBrightField, Williston, VT, USA) was used to estimate the density of PHF-tau ${ }_{\mathrm{AT}}$-ir and PHF-tau $\mathrm{PHF}$-1 - ir neurons with different patterns of staining in the CA3. Using the Neurolucida package, this region was traced in contiguous Nissl-stained sections with the $4 \mathrm{x}$ objective, and the complete surface was scanned with a $40 \mathrm{x}$ objective in successive and non-overlapping frames of $17,250 \mu \mathrm{m}^{2}$. All the PHF-tau ${ }_{\text {AT8 }}$-ir and PHF-tau ${ }_{\text {PHF-1- }}$ ir neurons were recorded and classified as type I or II (see Table 2).

Spearman's test was applied to study the possible correlation between the density of total neurons and the density of PHF-tau ${ }_{\text {AT8 }}$-ir neurons using the GraphPad Prism statistical package (Prism, San Diego, CA, USA).

\section{RESULTS}

\section{Patterns of PHF-tau immunostaining}

Thorny excrescences of CA3 neurons were labeled with the AT8 but not the PHF-1 antibody (Fig. 2), and we distinguished two patterns of PHF-tau ${ }_{\text {AT8 }}$ immunostaining, type I and II [20]. The type I pattern was characterized by diffuse cytoplasmic staining of neurons with no NFT but with an apparently normal morphology (Fig. 2 A-C; Fig. 3), although dendrites and proximal axons often displayed strong Golgi-like labeling (Fig. 1). Type II neurons contained NFT, although the amount of somatic cytoplasm occupied by the NFT varied (Fig. 2 D-F). Accordingly, while the dendritic arbour of neurons with relatively little NFT usually displayed numerous dendritic processes, neurons whose cytoplasm was full of NFT had very few dendritic processes, suggesting they were undergoing atrophy. Similarly, we also observed type I and II neurons with the PHF-tauPHF-1 antibody (Fig. 3), although unlike PHF-tau ${ }_{\mathrm{AT} 8}$, the proximal processes of PHF-tauPHF-1-immunoreactive (-ir) neurons were less profusely labeled and no thorny excrescences were stained (Table 2).

We used a Tau-1 antibody that recognizes a nonphosphorylated epitope of tau to verify that thorny excrescences were specifically labeled with PHFtau $_{\mathrm{AT}}$, and that no dephosphorylated tau was present in the thorny excrescences. Neurons were not immunostained for Tau-1, whereas the thorny excrescences of virtually all type I PHF-tau $\mathrm{AT}_{\mathrm{A}}$-ir neurons in adjacent sections were labeled (Fig. 4). However, when we examined whether type I PHF-tau ${ }_{\mathrm{AT} 8}$-ir neurons had 
Table 2

Labeling of thorny excrescences and density of type I and II PHF-tau ${ }_{\mathrm{AT}}$-ir neurons $\left(\mathrm{PHF}\right.$-tau $\mathrm{AT}_{\mathrm{AT}}$-ir neurons $/ \mathrm{mm}^{2}$ ) and PHF-tau aHF-1 -ir neurons

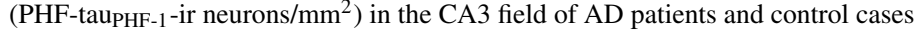

\begin{tabular}{|c|c|c|c|c|c|c|c|c|}
\hline \multirow[b]{2}{*}{$\begin{array}{l}\mathrm{AD} \\
\text { patient }\end{array}$} & \multicolumn{4}{|c|}{ PHF-tau ${ }_{\mathrm{AT} 8}$} & \multicolumn{4}{|c|}{ PHF-tauPHF-1 } \\
\hline & Type I & $\begin{array}{c}\text { Thorny } \\
\text { excrescences } \\
\text { labeling }\end{array}$ & Type II & $\begin{array}{c}\text { Thorny } \\
\text { excrescences } \\
\text { labeling }\end{array}$ & Type I & $\begin{array}{l}\text { Thorny } \\
\text { excrescences } \\
\text { labeling }\end{array}$ & Type II & $\begin{array}{c}\text { Thorny } \\
\text { excrescences } \\
\text { labeling }\end{array}$ \\
\hline $\mathrm{P} 1$ & 0.59 & All & 0.67 & 0 & 0 & 0 & 0.49 & 0 \\
\hline P3 & 0.41 & All & 0.13 & 0 & - & - & - & - \\
\hline P4 & 0.90 & All & 0 & 0 & 0 & 0 & 0.07 & 0 \\
\hline P5 & 0.59 & All & 0 & 0 & 0 & 0 & 0.33 & 0 \\
\hline P6 & 3.41 & All & 0.16 & 0 & 1.31 & 0 & 0 & 0 \\
\hline P7 & 4.18 & All & 0.96 & 0 & 0.53 & 0 & 1.06 & 0 \\
\hline $\mathrm{P} 8$ & 0 & 0 & 0 & 0 & 0.09 & 0 & 0 & 0 \\
\hline P9 & 5.03 & All & 3.41 & 0 & 1.09 & 0 & 2.54 & 0 \\
\hline P10 & 0.70 & All & 3.21 & 0 & 0 & 0 & 6.32 & 0 \\
\hline P11 & 2.35 & All & 0.73 & 0 & 0.67 & 0 & 0.47 & 0 \\
\hline \multicolumn{9}{|l|}{ Control } \\
\hline $\mathrm{C} 1$ & 0 & 0 & 0 & 0 & - & - & - & - \\
\hline $\mathrm{C} 2$ & 0.14 & All & 0 & 0 & 0.18 & 0 & 0.28 & 0 \\
\hline $\mathrm{C} 3$ & 0 & 0 & 0 & 0 & - & - & - & - \\
\hline $\mathrm{C} 4$ & 2.27 & All & 0.10 & 0 & 0.11 & 0 & 0.13 & 0 \\
\hline $\mathrm{C} 5$ & 0 & 0 & 0 & 0 & 0 & 0 & 0 & 0 \\
\hline C6 & 0 & 0 & 0 & 0 & - & - & - & - \\
\hline $\mathrm{C} 7$ & 0 & 0 & 0 & 0 & 0 & 0 & 0.09 & 0 \\
\hline
\end{tabular}

dendritic spines in other fields of the hippocampal formation and adjacent cortex (the dentate gyrus; CA1 and CA2 fields; the subiculum, presubiculum, and parasubiculum; fields of the subicular complex; entorhinal, perirhinal, and posterior parahippocampal cortex; and lateral neocortical Brodmann areas 10, 17, 18, 20, 21, 24), this was not the case in any of these regions (Fig. 1 Q). Thus, thorny excrescences are specifically labeled with PHF-tau AT8 $_{\text {in }}$ the CA3, suggesting that abnormal phosphorylation of tau in thorny excrescences is particularly relevant in AD.

Possible relationships between patterns of PHF-tau staining, neuronal loss, the presence of amyloid plaques, and labeling of thorny excrescences

Unbiased stereology was used to quantify the total

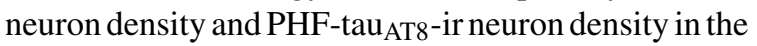
CA3 field of control and AD patients, and the density of $\mathrm{PHF}_{\text {-tau }} \mathrm{AT} 8$-ir neurons was represented as a percentage with respect to the total neuron density obtain per case (Fig. 5). No correlation was found between the density of total neurons and the density of PHF-tau $\mathrm{AT} 8$-ir neurons (Spearman's rho $-0.3766 ; P=0.3125$ ). Furthermore, we estimated the density of PHF-tau AT $^{-}$and PHF-tauPHF-1-ir neurons classified as displaying a type I or II pattern of immunostaining in the CA3 in each case (Fig. 6). By taking into account the data from Table 2 (see also Fig. 6), the highest density of pattern
II PHF-tau ${ }_{\mathrm{AT} 8}$-ir neurons were present at later stages of the disease, whereas the majority of these neurons displayed pattern I in earlier stages. In the case of PHFtauPHF-1-ir cells, the number and proportion of neurons with pattern I staining was relatively low at all stages, whereas numerous neurons with pattern II were found at later stages. Thus, the highest density of neurons with pattern II was found in the later stages.

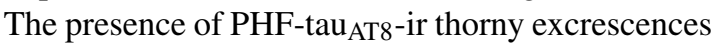
in CA3 neurons was independent of the intensity and number of PHF-tau ${ }_{\mathrm{AT} 8}$-ir processes in the hippocampus and dentate gyrus. Indeed, there was highly variable PHF-tau ${ }_{\mathrm{AT}}$ labeling in these structures, despite the presence of PHF-tau $\mathrm{AT}_{\mathrm{A} 8}$-ir thorny excrescences (Fig. 7).

Some PHF-tau ${ }_{\mathrm{AT}}$-ir thorny excrescences were so large that they had a dystrophic appearance when compared to those present in other adjacent neurons (Fig. 8C-E). Since amyloid plaques induce morphological changes in dendritic spines [23-26], we wondered if the presence of these giant thorny excrescences could reflect the fact that amyloid plaques were in contact or adjacent to these PHF-tau $\mathrm{AT} 8$-ir neurons. Thus, adjacent sections to those stained for PHFtau ${ }_{\text {AT8 }}$ were processed to visualize amyloid plaques (Fig. 8A). Comparing the distribution of PHF-tau AT8 $^{-}$ ir neurons and plaques revealed no such a correlation, since there were cases showing very few plaques in CA3 but a relatively large number PHF-tau ${ }_{\mathrm{AT}}$-ir neurons with large thorny excrescences (Fig. 8). 

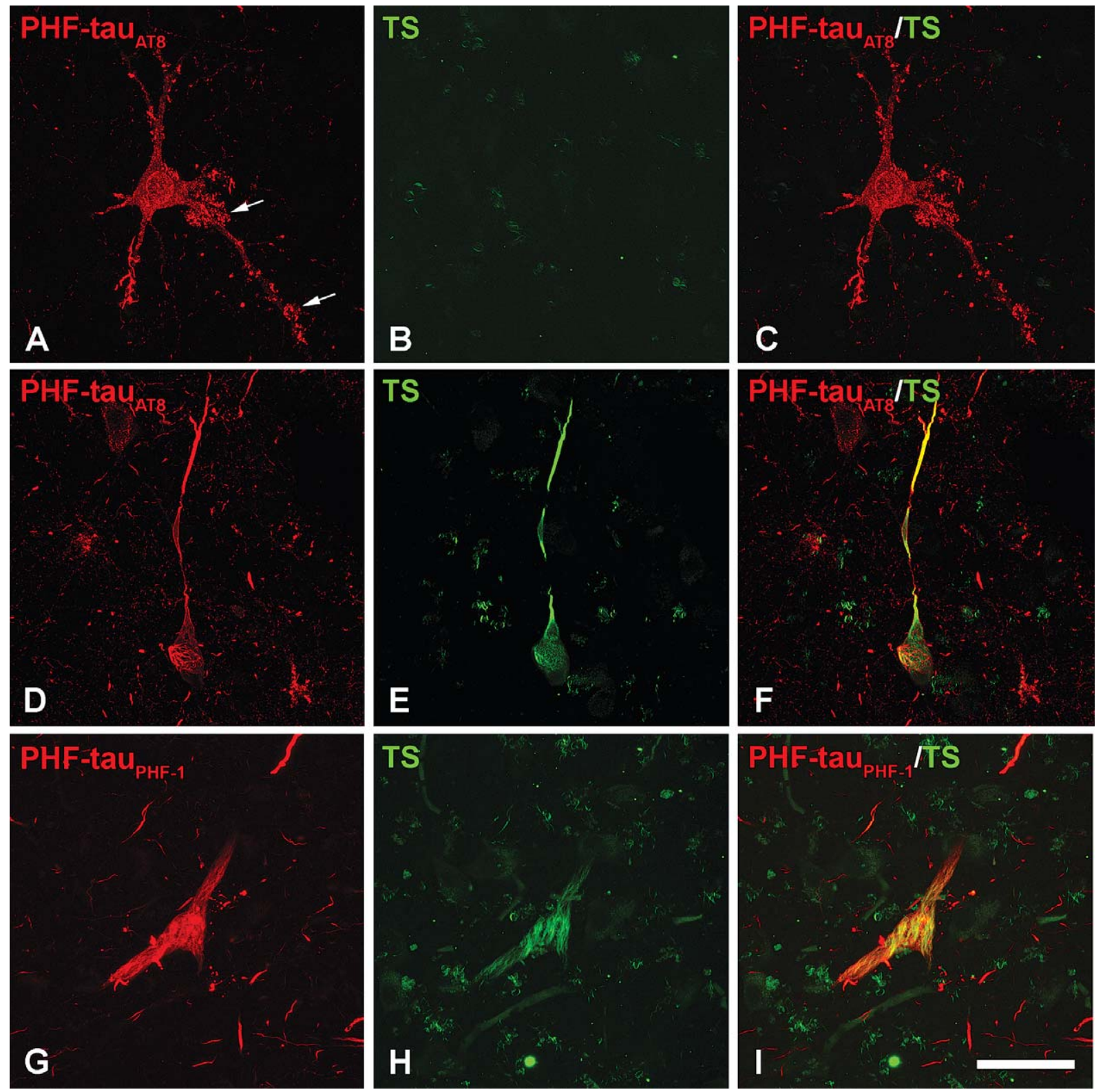

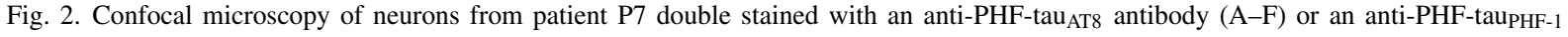

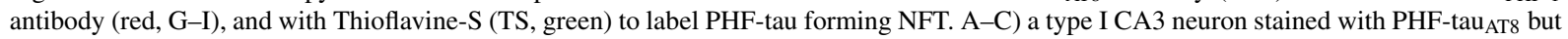
not forming NFT (stack of 41 confocal optical sections, step size: $0.6 \mu \mathrm{m}$ ). Arrows indicate some thorny excrescences. D-F) A type II where

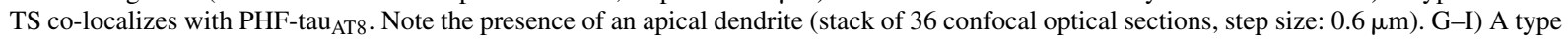
II neuron where TS co-localizes with PHF-taupHF-1 (stack of 28 confocal optical sections, step size: $0.45 \mu \mathrm{m}$ ). Scale bar (in I): $58 \mu \mathrm{m}$ in A-I.

Finally, to test whether tau phosphorylation correlates with a loss of synaptic connectivity, we examined glutamatergic (VGLUT-1) axon terminals to determine whether they innervated thorny excrescences of PHFtau $\mathrm{AT}_{8}$-ir neurons. Apparently normal VGLUT-1-ir boutons were in direct apposition to the PHF-tau $\mathrm{AT}_{\mathrm{A}}$-ir thorny excrescences, suggesting a "normal" connectivity (Fig. 9). Hence, tau phosphorylation in thorny excrescences is likely to be an early marker and a reversible even.

\section{DISCUSSION}

The main finding in the present study is that the typical thorny excrescences of CA3 neurons are labeled 

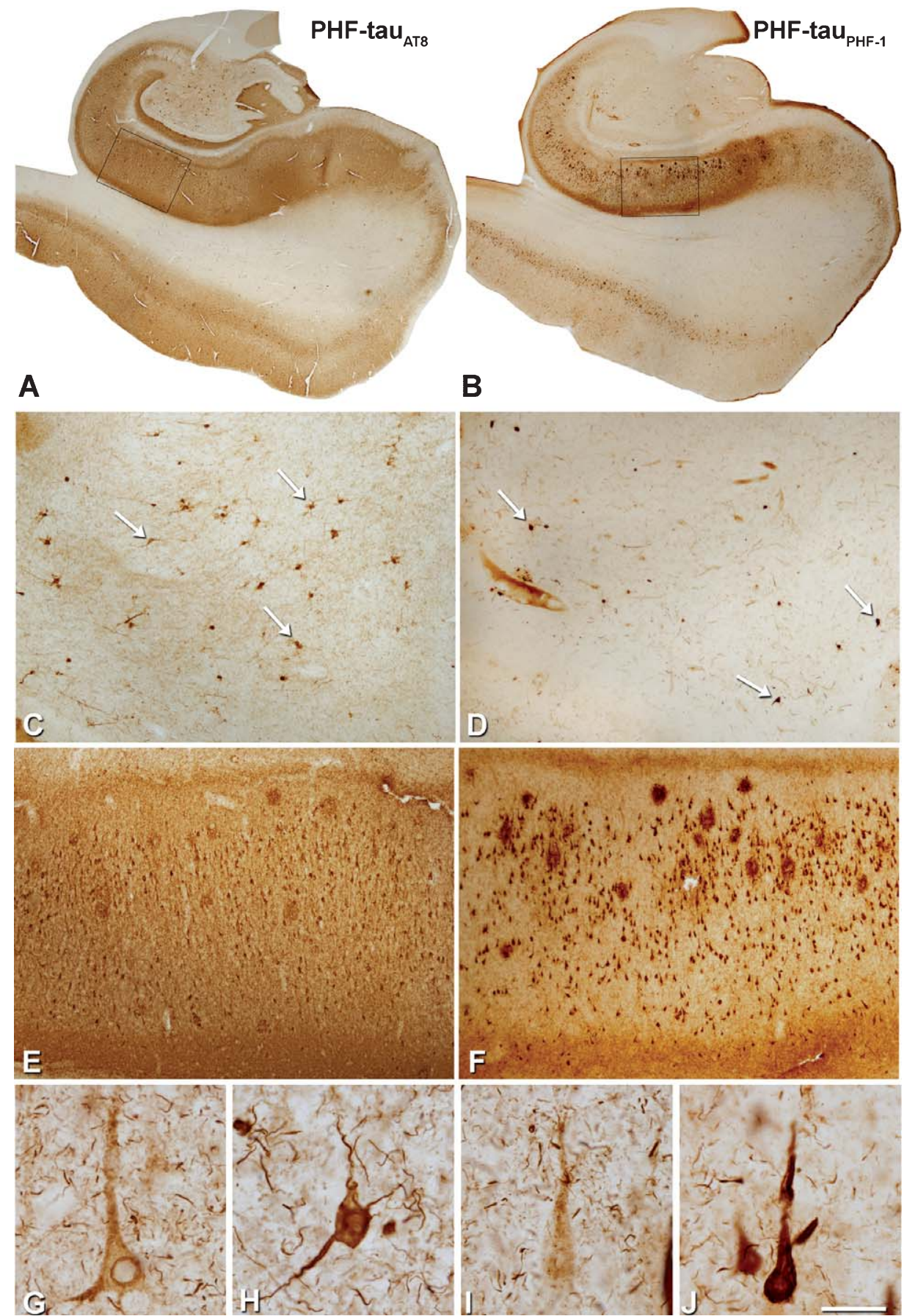

Fig. 3. Low-power photomicrographs of sections from the hippocampal formation of patient P9 stained with PHF-tau (B). C and D) Higher magnification of the CA3 field in A and B, respectively. Arrows indicate some labeled neurons. Note that the density of PHF-tau ${ }_{\mathrm{AT}}$-ir neurons is higher than that of PHF-tau PHF-1-ir neurons. E and F) Higher magnification of the boxed CA1 fields in A and B, respectively. G-J) Higher magnification of PHF-tau $\mathrm{AT}$-ir $(\mathrm{G}, \mathrm{H})$ and PHF-tau PHF-1-ir (I-J) type I (G and I) and II (H and J) stained neurons. Scale bar (in J): $1600 \mu \mathrm{m}$ in A, B; $320 \mu \mathrm{m}$ in C-F; $35 \mu \mathrm{m}$ in G-J.

selectively using the AT8 but not the PHF-1 antibody. Thus, these particular dendritic spines must be involved in specific activities that fail in AD.

\section{Expression of PHF-tau in thorny excrescences}

We observed numerous CA3 neurons with their thorny excrescences clearly labeled by the AT8 (PHF- 

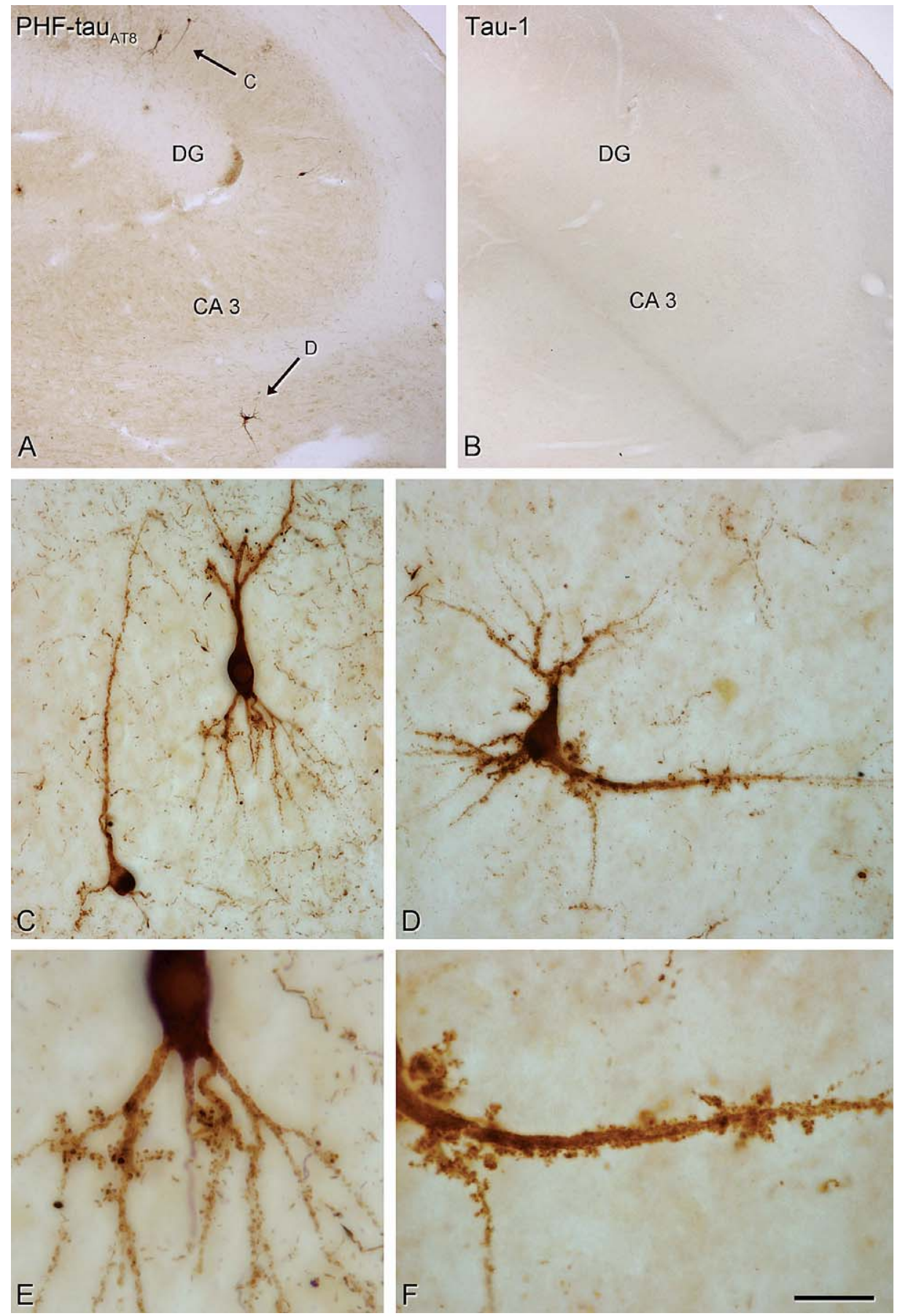

Fig. 4. A and B) Low-power photomicrographs of sections from the hippocampal formation of patient P5 stained with PHF-tau ${ }_{\text {AT8 }}$ (A) and Tau-1 (antibody against non-phosphorylated tau protein) (B). The arrows in A indicate the cells shown at higher magnification in C and D. E and F) Examples of thorny excrescences PHF-tau $\mathrm{AT}_{8}$-ir observed in C and D, respectively. Scale bar (in F): $400 \mu \mathrm{m}$ in A-B; $43 \mu \mathrm{m}$ in C-D; $11 \mu \mathrm{m}$ in $\mathrm{E} ; 23 \mu \mathrm{m}$ in $\mathrm{F}$.

$\operatorname{tau}_{\mathrm{AT} 8}$ ) antibody. Despite the wealth of studies of AD, it is surprising that PHF-tau ${ }_{\mathrm{AT} 8}$-ir thorny excrescences have not been described before. It is possible that they have passed unnoticed when labeled previously or that technical issues influence their labeling with this antibody. For example, it is common to use for- 

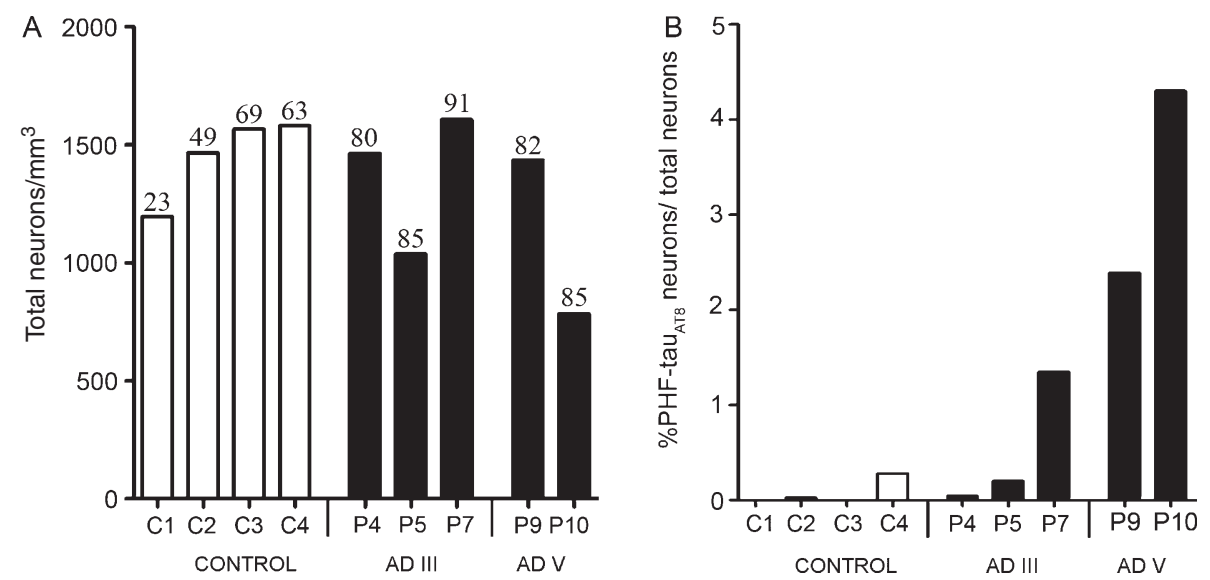

Fig. 5. A) Graph showing the density of total neurons (total neurons $/ \mathrm{mm}^{3}$ ) in control cases (white columns) and AD patients (black columns) with different NF stages. In the top of the bars is indicated the age of each individual. B) Graph showing the percentage of PHF-tau ${ }_{\mathrm{AT}}$-ir neurons in the same cases.

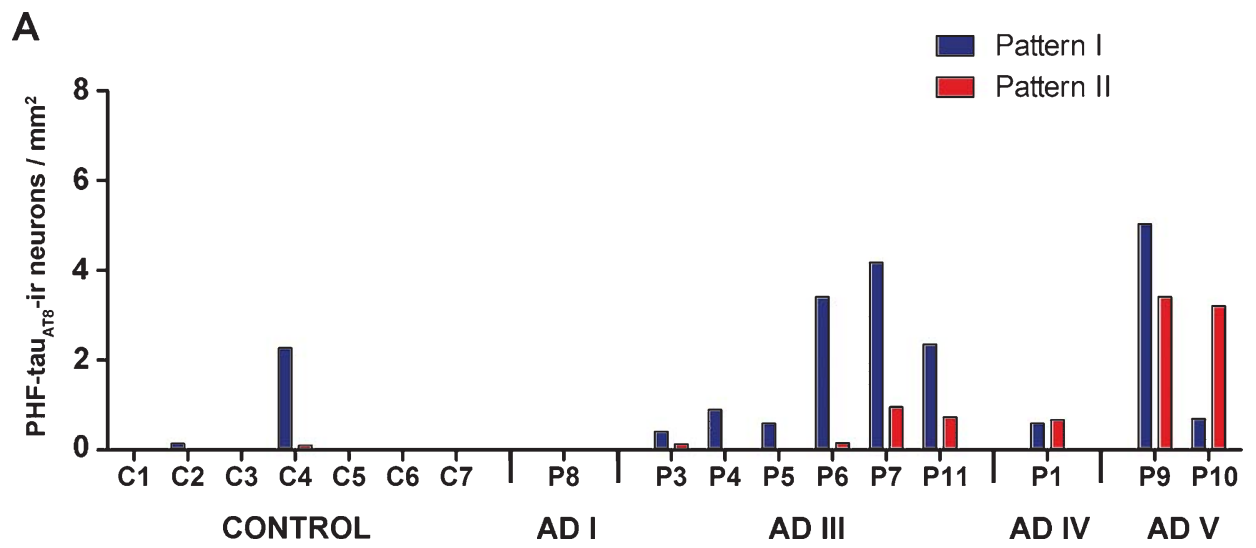

B

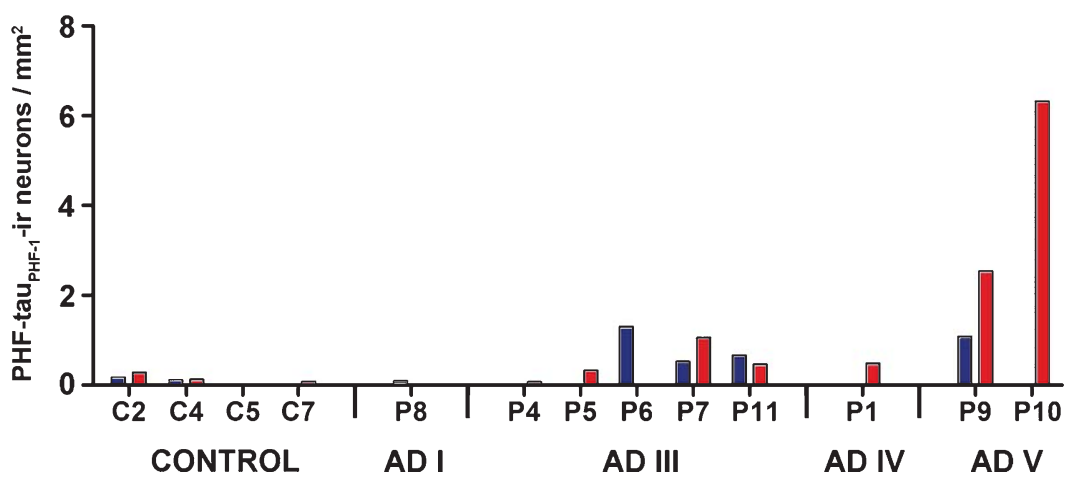

Fig. 6. Graphs showing the density of PHF-tau $\mathrm{AT}_{8}$-ir (A) and PHF-tau $\mathrm{PHF}-1$-ir neurons (B) in the CA3 field from control cases and AD patients with different NF stages.

malin (10\%) fixed, paraffin embedded tissue, heated in a microwave oven prior to immunocytochemical staining. By contrast, we used vibratome sections of fresh brain tissue fixed in paraformaldehyde (4\%) and immunocytochemistry was performed in freefloating sections. Furthermore, the post-mortem period 

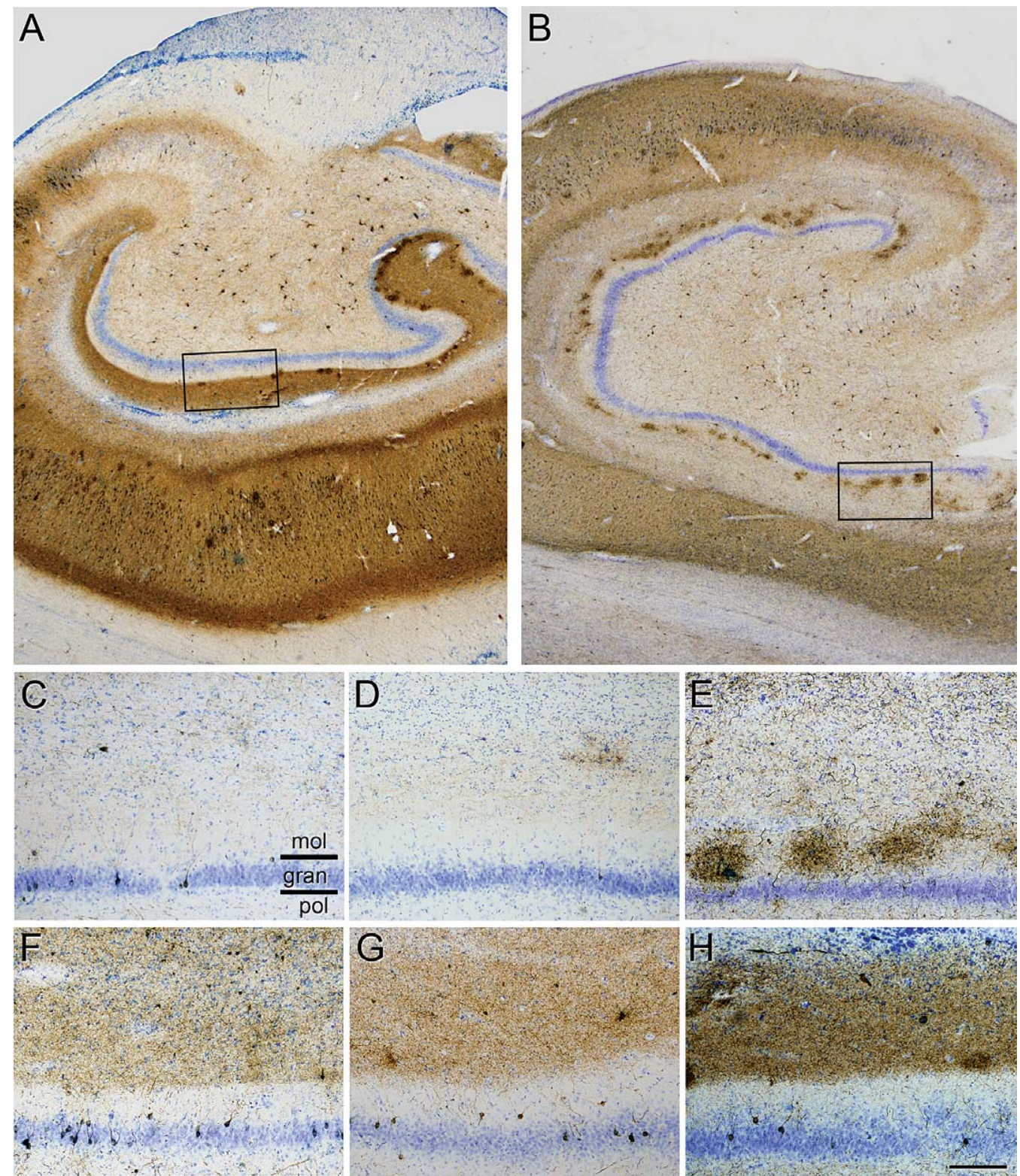

Fig. 7. Photomicrographs of anti-PHF-tau ${ }_{\text {ATs }}$ stained sections counterstained with the Nissl technique showing different fields of the hippocampal formation of patients P9 (A) and P10 (B). Boxed areas in A and B correspond to panels $\mathrm{H}$ and E, respectively. C-H) Higher magnification of the dentate gyrus of patients P6, P5, P10, P7, P11 and P9, respectively. Scale bar (in H): $700 \mu \mathrm{m}$ in A, B; $130 \mu \mathrm{m}$ in C-H. gran = granular layer; $\mathrm{mol}=$ molecular layer; pol = polymorphic layer.

of autopsy samples (10-18 h) is significantly longer than in our own research (less than $3 \mathrm{~h}$ ). Whatever the reason, we consistently observed PHF-tau $\mathrm{AT}_{\mathrm{T}}$-ir thorny excrescences in the CA3 field of patients at different stages of $\mathrm{AD}$, ages, and gender, using immunoperoxidase or immunofluorescence methods (Table 1). Since we examined relatively few cases $(n=11)$, we consider this finding to be very robust in the general population of $\mathrm{AD}$ patients.

\section{Evolution of the alterations to the tau protein and of the labeling of thorny excrescences}

In the $\mathrm{AD}$ brain, 45 different sites in the tau molecule can be phosphorylated [27], some of which can be identified by different antibodies like AT8 (S199/S202/T205) or PHF-1 (S396/S404). This phosphorylation at different sites seems to occur in a sequentially ordered cascade during the progression 


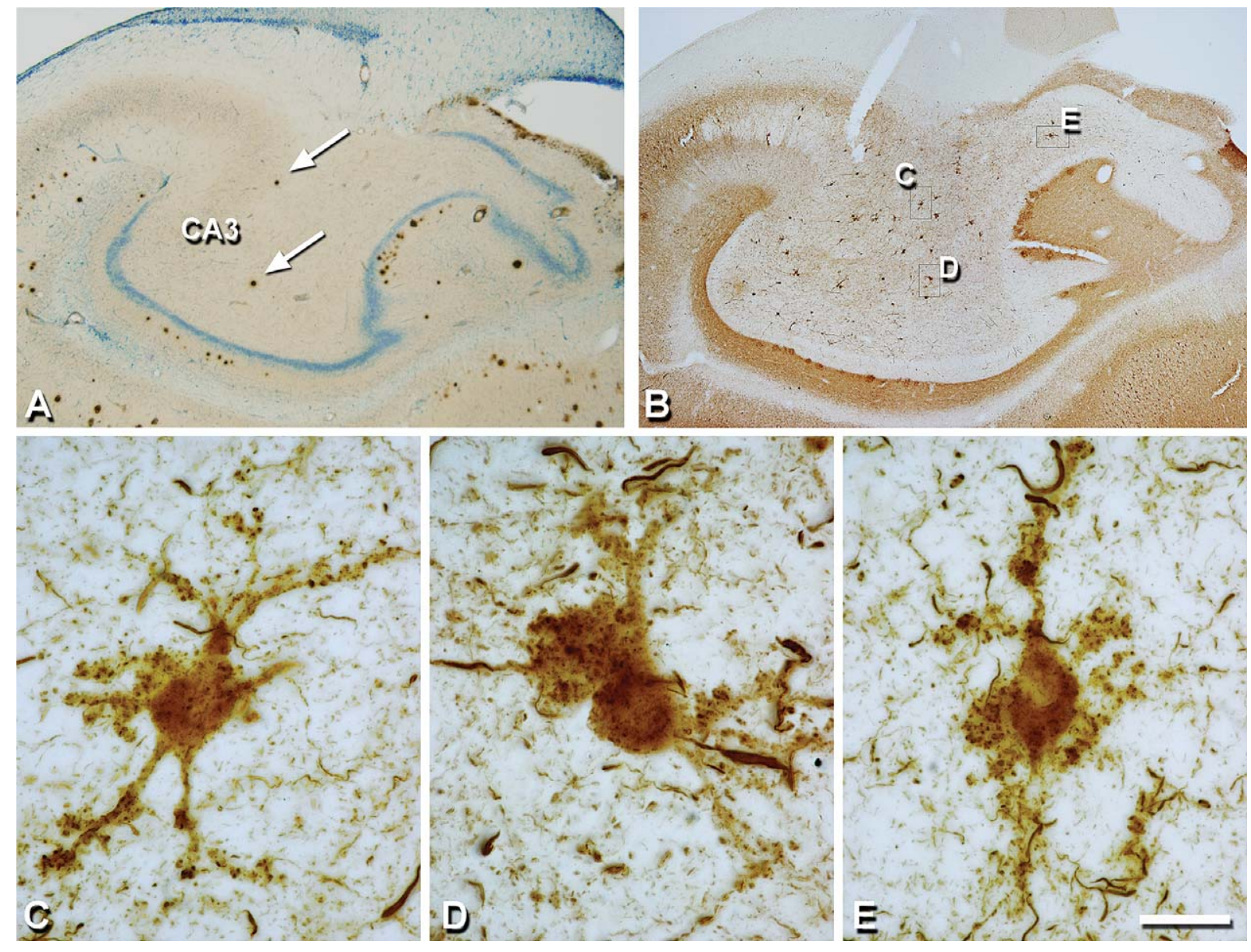

Fig. 8. Amyloid- $\beta$ plaques and labeling of thorny excrescences. A and B) Photomicrographs illustrating the distribution of $A \beta$ plaques in a Niss counterstained section and of PHF-tauAT8-ir neurons in the CA3 field of an adjacent section from patient P9. C-E) High-power photomicrographs of some type I PHF-tau ${ }_{\mathrm{AT}}$-ir neurons highlighted by boxes in B. Note that there are relatively few A $\beta$ plaques in CA3 (arrows in A), whereas numerous neurons show type I PHF-tau ${ }_{\mathrm{AT}}$-ir with labeled thorny excrescences (C-E). Scale bar (in E): $198 \mu \mathrm{m}$ in A, B; $25 \mu \mathrm{m}$ in C-E.

of the disease. Indeed, it has been proposed that at the level of individual neurons, there is an early stage (termed the pre-tangle stage) that is characterized by the accumulation of PHF-tau protein in the somatodendritic domain of affected neurons. These neurons are non-argyrophilic and therefore they can only be detected with anti-PHF-tau antibodies. The next stage involves the appearance of classic intracellular NFT, while in the final stage ghost NFT accumulate, defined as NFT located "freely" in the neuropil with no relationship to a neuronal soma $[4,28]$. Previous studies have shown that interaction with the AT8 antibody is frequently observed in neurons of patients at an early stage of the disease, whereas PHF-1 epitopes are more frequently observed at later stages of the disease [29-32].
In the present work, we found that the highest density of pattern II PHF-tau ${ }_{\mathrm{AT} 8}$-ir neurons were present at later stages of the disease, whereas in the earlier stages the majority of PHF-tau ${ }_{\mathrm{AT}}$-ir neurons displayed pattern I. When considering PHF-tau ${ }_{\mathrm{PHF}-1}$-ir cells, there are always relatively few type I neurons, whereas the number of type II neurons increases at later stages such that the highest density and proportion of type II neurons were found in the later stages. This observation is in line with previous indications suggesting that the phosphorylation of tau at the site recognized by AT8 (mostly pre-tangle neurons) precedes that of PHF-1 phosphorylation (mostly neurons with tangles). Our dual fluorescence immunohistochemistry and histochemistry indicates that type I staining is due to the accumulation of unpolymerized PHF-tau, whereas the 

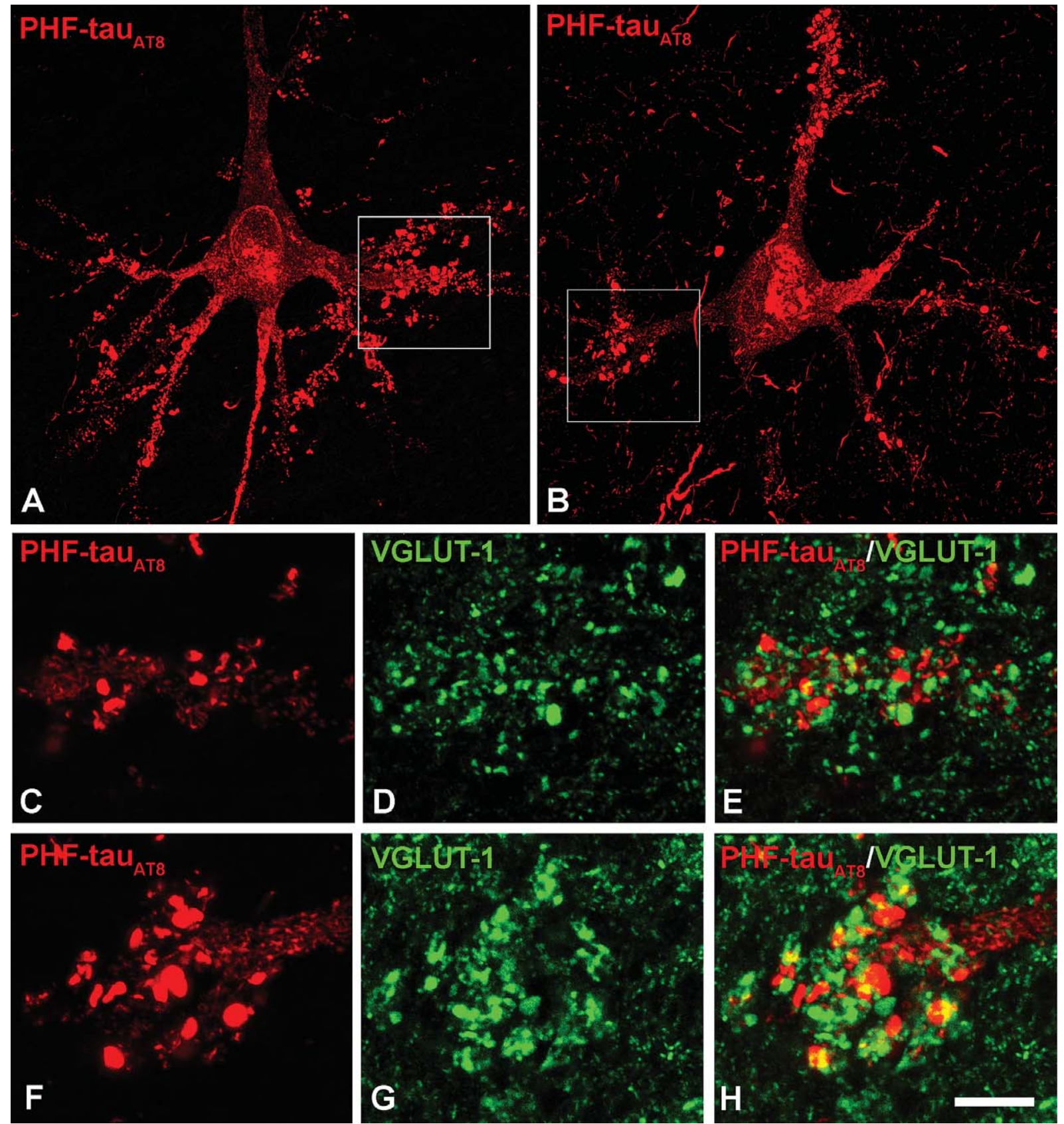

Fig. 9. A and B) Stacks of 49 confocal optical sections (A) and 29 optical sections (B) (step size: 0.5 and $0.8 \mu \mathrm{m}$, respectively) from type I PHF-tau $\mathrm{AT}_{8}$-ir pyramidal neurons in the CA3 of patients P4 and P7, respectively. Squares in A and B indicate the regions shown at higher magnification in C-E ( 4 confocal optical sections, step size: $0.46 \mu \mathrm{m}$ ) and F-H (3 confocal optical sections, step size: $0.80 \mu \mathrm{m})$, respectively, illustrating the VGLUT-1-ir glutamatergic axon terminals (green) that innervate dendritic excrescences of PHF-tau ${ }_{\text {AT8-ir }}$ pyramidal neurons (red). Scale bar (in $\mathrm{H}): 23 \mu \mathrm{m}$ in A, B; $7 \mu \mathrm{m}$ in $\mathrm{C}-\mathrm{H}$

type II pattern is due to the accumulation of polymerized PHF-tau into NFT. Therefore, it seems that PHF-tau $_{\mathrm{AT} 8}$ and PHF-tau $\mathrm{PHF}-1$-ir type I neurons represent pre-tangle stages and the type II neurons are in tangle stages. However, we cannot rule out the possibility that these neurons represent independent stages and not a sequence in the destruction of the cytoskeleton in individual neurons. 
Possible functional significance of aberrant tau phosphorylation in thorny excrescences

Tau is a microtubule-associated protein, whereas dendritic spines have an actin-based cytoskeleton. However, the presence of microtubule proteins in spines, like tau, could be explained by the occasional presence of microtubules in longer CA3 dendritic spines [33, 34]. Moreover, microtubules could be present transiently in spines, and they may play a role in the control and regulation of dendritic spine development and plasticity [35]. In addition, F-actin is an important component of dendritic spines [36] and tauinduced degeneration may provoke the accumulation of F-actin, leading to a direct interaction between tau and actin [37]. We now suggest that dendritic spine plasticity could be modified by the presence of PHFtau, a phosphoprotein that could remain in the spine due to its interaction with cofilin [38]. In addition, it was recently indicated that tau mislocation to dendritic spines mediates synaptic dysfunction in mouse models [39]. PHF-tau $\mathrm{AT}$, like proline directed phosphorylation, could induce the mislocalization of tau to dendritic spines, where it impairs excitatory synaptic transmission through the loss of functional surface glutamate receptors [39]. Furthermore, an association of the tau protein with the PSD complex has been reported, concentrating NMDA receptors to PSD95 [40]. All these results suggest a role for tau in dendrites in those mouse models, although we cannot exclude that a similar mechanism to that reported by Hoover et al. [39] could occur in the AD patients studied here.

We do not know the principal cause for tau phosphorylation at the site recognized by the AT8 antibody, although A $\beta$ oligomers may activate GSK3 [41, 42] that is the kinase that modifies the AT8 site [27]. However, we have not found a correlation between $\mathrm{A} \beta$ plaques and the labeling of thorny excrescences, although we cannot rule out that small oligomers induce tau phosphorylation in these particular dendritic spines. Whatever the mechanism, thorny excrescences are a major synaptic target of granule cell (mossy fibers) axons, which receive most of their extrinsic input from layer II neurons of the entorhinal cortex and participate in a critical pathway to transfer neocortical representations to the hippocampus [18]. Therefore, these structures may play an essential role in the memory impairment typical of $\mathrm{AD}$ patients. Indeed, although glutamatergic innervation of these spines seems to remain unchanged, alterations in the synaptic connections may exist at the physiological level, and further studies on animal models will be necessary to resolve this question.

The studies of the relationship between synaptic plasticity and modifications in tau phosphorylation in the European ground squirrel [43] may be relevant when interpreting the present results. In these animals, synapses of mossy fibers onto CA3 hippocampal neurons undergo cyclic changes during hibernation and arousal such that there is a partial denervation of CA3 pyramidal neurons during torpor that is fully and rapidly reversed during euthermy [44]. There is an induction of PHF-like phosphorylation in the brain when these animals hibernate, which is similar to the characteristic increase in tau phosphorylation [45]. Furthermore, the changes in the denervation/reinnervation of CA3 pyramidal neurons by mossy fibers during hibernation/arousal are associated with reversible PHF-like phosphorylation of tau that occurs over a similar time course. Thus, the formation and degradation of PHF-like tau might represent a physiological mechanism not necessarily associated with pathological effects but rather with neuronal plasticity.

Intriguingly, the aberrant phosphorylation of thorny excrescences observed here might be induced by the failure of synaptic connections or by diminished synaptic activity of neurons in the dentate gyrus and CA3. Such changes may be due to the impairment of entorhinal connections with the dentate gyrus, which could produce the early alterations in declarative memory in AD patients. Nevertheless, the presence of CA3 neurons with PHF-tau ${ }_{\mathrm{AT}}$-ir thorny excrescences was independent of the intensity and number of PHF-tau $\mathrm{AT}_{\mathrm{B}}$-ir processes present in the outer twothirds of the molecular layer in the dentate gyrus, a major site where layer II entorhinal neurons terminate [46]. However, physiological alterations to the entorhinal/hippocampus connections may precede the expression of PHF-tau in the entorhinal axons that terminate in the dentate gyrus.

In conclusion, we demonstrate the presence PHFtau in thorny excrescences in the brain of AD patients. This is a novel feature of AD and it could be a very early marker of disease onset, possibly representing the first step in impaired synaptic transmission [39].

\section{ACKNOWLEDGMENTS}

The authors are grateful to Lorena Valdés for technical assistance. This work was supported by grants from the following entities: CIBERNED (CB06/05/0066), 
Fundación CIEN (Financiación de Proyectos de Investigación de Enfermedad de Alzheimer y enfermedades relacionadas 2008), Fundación Caixa (BM05-47-0), the Spanish Ministerio de Ciencia e Innovación (SAF2009-09394).

Authors' disclosures available online (http://www.jalz.com/disclosures/view.php?id=874).

\section{REFERENCES}

[1] Grundke-Iqbal I, Iqbal K, Tung YC, Quinlan M, Wisniewski HM, Binder LI (1986) Abnormal phosphorylation of the microtubule-associated protein tau (tau) in Alzheimer cytoskeletal pathology. Proc Natl Acad Sci U S A 83, 49134917.

[2] Li B, Yamamori H, Tatebayashi Y, Shafit-Zagardo B, Tanimukai H, Chen S, Iqbal K, Grundke-Iqbal I (2008) Failure of neuronal maturation in Alzheimer disease dentate gyrus. J Neuropathol Exp Neurol 67, 78-84.

[3] Toni N, Laplagne DA, Zhao C, Lombardi G, Ribak CE, Gage FH, Schinder AF (2008) Neurons born in the adult dentate gyrus form functional synapses with target cells. Nat Neurosci 11, 901-907.

[4] Braak E, Braak H, Mandelkow EM (1994) A sequence of cytoskeleton changes related to the formation of neurofibrillary tangles and neuropil threads. Acta Neuropathol 87, 554-567.

[5] Delacourte A, David JP, Sergeant N, Buee L, Wattez A, Vermersch P, Ghozali F, Fallet-Bianco C, Pasquier F, Lebert F Petit H, Di Menza C (1999) The biochemical pathway of neurofibrillary degeneration in aging and Alzheimer's disease. Neurology 52, 1158-1165.

[6] Tolnay M, Probst A (1999) Review: tau protein pathology in Alzheimer's disease and related disorders. Neuropathol Appl Neurobiol 25, 171-187.

[7] Cajal SR (1893) Estructura del asta de Ammon y fascia dentata. Anales de la Sociedad española de Historia Natural (Actas) tomo XXII (tomo II, 2.a serie), 53-114.

[8] Lorente de Nó R (1934) Studies on the structure of the cerebral cortex. II. Continuation of the study of the ammonic system. $J$ Psychol Neurol 45, 381-442.

[9] Blackstad TW, Kjaerheim A (1961) Special axo-dendritic synapses in the hippocampal cortex: electron and light microscopic studies on the layer of mossy fibers. J Comp Neurol 117, 133-159.

[10] Amaral DG (1978) A Golgi study of cell types in the hilar region of the hippocampus in the rat. J Comp Neurol 182, 851-914.

[11] Tombol T, Somogyi G, Hajdu F, Madarasz M (1978) Granule cells, mossy fibres and pyramidal neurons: an electron microscopic study of the cat's hippocampal formation, I. Acta Morphol Acad Sci Hung 26, 291-310.

[12] Frotscher M, Gahwiler BH (1988) Synaptic organization of intracellularly stained CA3 pyramidal neurons in slice cultures of rat hippocampus. Neuroscience 24, 541-551.

[13] Frotscher M, Seress L, Schwerdtfeger WK, Buhl E (1991) The mossy cells of the fascia dentata: a comparative study of their fine structure and synaptic connections in rodents and primates. J Comp Neurol 312, 145-163.

[14] Seress L, Ribak CE (1995) Postnatal development of CA3 pyramidal neurons and their afferents in the Ammon's horn of rhesus monkeys. Hippocampus 5, 217-231.
[15] Buckmaster PS, Amaral DG (2001) Intracellular recording and labeling of mossy cells and proximal CA3 pyramidal cells in macaque monkeys. J Comp Neurol 430, 264-281.

[16] Gonzales RB, DeLeon Galvan CJ, Rangel YM, Claiborne BJ (2001) Distribution of thorny excrescences on CA3 pyramidal neurons in the rat hippocampus. J Comp Neurol 430, 357 368.

[17] Lauer M, Senitz D (2006) Dendritic excrescences seem to characterize hippocampal CA3 pyramidal neurons in humans. J Neural Transm 113, 1469-1475.

[18] Andersen P, Morris, R, Amaral, D, Bliss, T, O'Keefe, J (eds) (2007) The Hippocampus Book, Oxford University Press, New York.

[19] Braak H, Braak E (1991) Neuropathological stageing of Alzheimer-related changes. Acta Neuropathol 82, 239-259.

[20] Blazquez-Llorca L, Garcia-Marin V, DeFelipe J (2010) Pericellular innervation of neurons expressing abnormally hyperphosphorylated tau in the hippocampal formation of Alzheimer's disease patients. Front Neuroanat 4, 20.

[21] Porzig R, Singer D, Hoffmann R (2007) Epitope mapping of mAbs AT8 and Tau5 directed against hyperphosphorylated regions of the human tau protein. Biochem Biophys Res Сотmun 358, 644-649.

[22] Greenberg SG, Davies P, Schein JD, Binder LI (1992) Hydrofluoric acid-treated tau PHF proteins display the same biochemical properties as normal tau. J Biol Chem 267, 564569.

[23] Tsai J, Grutzendler J, Duff K, Gan WB (2004) Fibrillar amyloid deposition leads to local synaptic abnormalities and breakage of neuronal branches. Nat Neurosci 7, 1181-1183.

[24] Spires TL, Meyer-Luehmann M, Stern EA, McLean PJ, Skoch J, Nguyen PT, Bacskai BJ, Hyman BT (2005) Dendritic spine abnormalities in amyloid precursor protein transgenic mice demonstrated by gene transfer and intravital multiphoton microscopy. J Neurosci 25, 7278-7287.

[25] Knafo S, Alonso-Nanclares L, Gonzalez-Soriano J, MerinoSerrais P, Fernaud-Espinosa I, Ferrer I, DeFelipe J (2009a) Widespread changes in dendritic spines in a model of Alzheimer's disease. Cereb Cortex 19, 586-592.

[26] Knafo S, Venero C, Merino-Serrais P, Fernaud-Espinosa I, Gonzalez-Soriano J, Ferrer I, Santpere G, DeFelipe J (2009b) Morphological alterations to neurons of the amygdala and impaired fear conditioning in a transgenic mouse model of Alzheimer's disease. J Pathol 219, 41-51

[27] Hanger DP, Anderton BH, Noble W (2009) Tau phosphorylation: the therapeutic challenge for neurodegenerative disease. Trends Mol Med 15, 112-119.

[28] Bancher C, Brunner C, Lassmann H, Budka H, Jellinger $\mathrm{K}$, Wiche G, Seitelberger F, Grundke-Iqbal I, Iqbal K, Wisniewski HM (1989) Accumulation of abnormally phosphorylated tau precedes the formation of neurofibrillary tangles in Alzheimer's disease. Brain Res 477, 90-99.

[29] Kimura T, Ono T, Takamatsu J, Yamamoto H, Ikegami K, Kondo A, Hasegawa M, Ihara Y, Miyamoto E, Miyakawa T (1996) Sequential changes of tau-site-specific phosphorylation during development of paired helical filaments. Dementia 7, 177-181.

[30] Augustinack JC, Schneider A, Mandelkow EM, Hyman BT (2002) Specific tau phosphorylation sites correlate with severity of neuronal cytopathology in Alzheimer's disease. Acta Neuropathol 103, 26-35.

[31] Hernandez F, Lucas JJ, Cuadros R, Avila J (2003) GSK-3 dependent phosphoepitopes recognized by PHF- 1 and AT- 8 antibodies are present in different tau isoforms. Neurobiol Aging 24, 1087-1094. 
[32] Maurage CA, Sergeant N, Ruchoux MM, Hauw JJ, Delacourte A (2003) Phosphorylated serine 199 of microtubuleassociated protein tau is a neuronal epitope abundantly expressed in youth and an early marker of tau pathology. Acta Neuropathol 105, 89-97.

[33] Chicurel ME, Harris KM (1992) Three-dimensional analysis of the structure and composition of CA3 branched dendritic spines and their synaptic relationships with mossy fiber boutons in the rat hippocampus. J Comp Neurol 325, 169-182.

[34] Sorra KE, Harris KM (2000) Overview on the structure, composition, function, development, and plasticity of hippocampal dendritic spines. Hippocampus 10, 501-511.

[35] Gu J, Firestein BL, Zheng JQ (2008) Microtubules in dendritic spine development. J Neurosci 28, 12120-12124.

[36] Hering H, Sheng M (2001) Dendritic spines: structure, dynamics and regulation. Nat Rev Neurosci 2, 880-888.

[37] Fulga TA, Elson-Schwab I, Khurana V, Steinhilb ML, Spires TL, Hyman BT, Feany MB (2007) Abnormal bundling and accumulation of F-actin mediates tau-induced neuronal degeneration in vivo. Nat Cell Biol 9, 139-148.

[38] Whiteman IT, Gervasio OL, Cullen KM, Guillemin GJ, Jeong EV, Witting PK, Antao ST, Minamide LS, Bamburg JR, Goldsbury C (2009) Activated actin-depolymerizing factor/cofilin sequesters phosphorylated microtubule-associated protein during the assembly of alzheimer-like neuritic cytoskeletal striations. J Neurosci 29, 12994-13005.

[39] Hoover BR, Reed MN, Su J, Penrod RD, Kotilinek LA, Grant MK, Pitstick R, Carlson GA, Lanier LM, Yuan LL, Ashe KH, Liao D (2010) Tau mislocalization to dendritic spines mediates synaptic dysfunction independently of neurodegeneration. Neuron 68, 1067-1081.

[40] Ittner LM, Ke YD, Delerue F, Bi M, Gladbach A, van Eersel J, Wolfing H, Chieng BC, Christie MJ, Napier IA, Eckert A, Staufenbiel M, Hardeman E, Gotz J (2010) Dendritic function of tau mediates amyloid-beta toxicity in Alzheimer's disease mouse models. Cell 142, 387-397.

[41] Townsend M, Mehta T, Selkoe DJ (2007) Soluble Abeta inhibits specific signal transduction cascades common to the insulin receptor pathway. J Biol Chem 282, 33305-33312.

[42] Magdesian MH, Carvalho MM, Mendes FA, Saraiva LM, Juliano MA, Juliano L, Garcia-Abreu J, Ferreira ST (2008) Amyloid-beta binds to the extracellular cysteine-rich domain of Frizzled and inhibits Wnt/beta-catenin signaling. J Biol Chem 283, 9359-9368.

[43] Arendt T, Stieler J, Strijkstra AM, Hut RA, Rudiger J, Van der Zee EA, Harkany T, Holzer M, Hartig W (2003) Reversible paired helical filament-like phosphorylation of tau is an adaptive process associated with neuronal plasticity in hibernating animals. J Neurosci 23, 6972-6981.

[44] Popov VI, Bocharova LS (1992) Hibernation-induced structural changes in synaptic contacts between mossy fibres and hippocampal pyramidal neurons. Neuroscience 48, 53-62.

[45] Avila J, Lucas JJ, Perez M, Hernandez F (2004) Role of tau protein in both physiological and pathological conditions. Physiol Rev 84, 361-384.

[46] Witter MP, Amaral DG (1991) Entorhinal cortex of the monkey: V. Projections to the dentate gyrus, hippocampus, and subicular complex. J Comp Neurol 307, 437-459. 